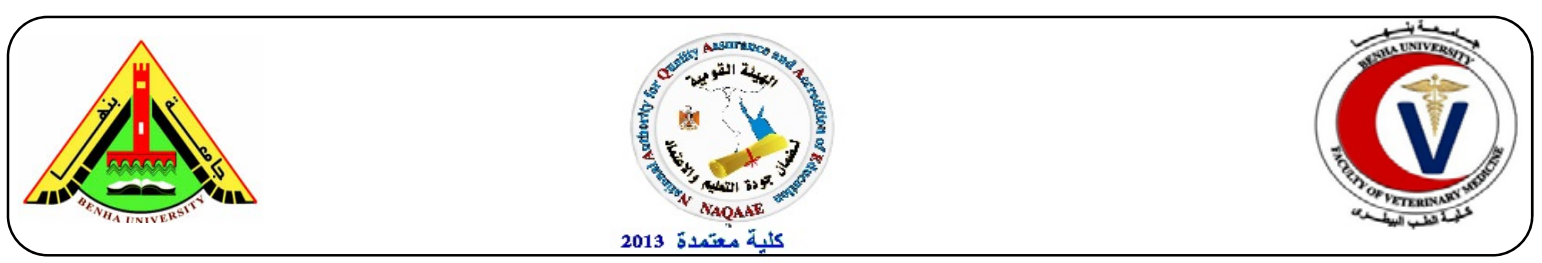

\title{
Effect of some factors on prevalence of FMDV antigen in both cattle and buffaloes in Egypt
}

\author{
Hassan A. Aidaros ${ }^{1}$, Mona M.A. Ashoub ${ }^{1}$, Hiam M. Fakhry², Hala G. A. EI Daous ${ }^{1}$ \\ ${ }^{1}$ Department of Animal, Poultry and Environmental Hygiene, Faculty of Vet. Med., Benha University, \\ ${ }^{2}$ Department of foot and mouth disease at Veterinary Serum and Vaccine Research Institute, Abbassia, \\ Cairo
}

\section{A B S T R A C T}

The present study was carried out for detection and identification of the isolated FMDV from infected tissue samples using serotyping antigen detection ELISA kit (IZSLER ELISA Kit).Thirty six lesion samples were collected from different localities (Menofia, Gharbia, Kalyoubia, Giza and Sharquia governorates) during the period from May 2014 to July 2015.The obtained results indicated that clinically, unvaccinated infected cattle in Gharbia governorate 2014were positive to FMDV infection serotype O. Samples collected from infected, vaccinated cattle and buffaloes in Kalyoubia governorate during 2015 were positive to FMDV infection serotype O. Clinically infected cattle and buffaloes in Menofia governorate during 2015 seven samples were positive to FMDV infection, which serotyped as five samples were serotype O \& two samples were SAT-2. Clinically infected cattle and buffaloes in Giza governorate during 2015 sixteen samples were positive to FMDV infection, which eight samples from them serotyped as SAT-2 \& seven samples from them were serotype O \& one of them was serotyped A. Clinically infected un vaccinated cattle in Sharquia governorate 2015 three samples were positive to FMDV infection serotype A. We concluded that large number of both vaccinated and un vaccinated animals in these governorates affected by FMDV infection by its different serotypes in the period of the study, and there are different factors affecting prevalence of FMDV as (age, state of vaccination, type of vaccination, sex, season and species).

Keywords: FMD, Antigen detection ELISA, tongue epithelium.

(BVMJ-30(1): 341-347, 2016)

\section{INTRODUCTION}

$\mathrm{F}$ oot-and-mouth disease is a sever, clinically acute, vesicular disease of cloven-hoofed animals including domesticated ruminants and pigs, in addition to more than 70 wildlife species (Coetzer et al., 1994). The etiological agent (FMDV) being a non-enveloped, icosahedral virus, $26 \mathrm{~nm}$ in diameter, containing positive sense RNA of around $8.4 \mathrm{~kb}$. Viral RNA is translated into a poly protein during intracellular and cytoplasmic replication, which resulted in proteolytical cleaved into 12 structural and non-structural proteins. The complete viral capsid consists of 60 copies of each four structural proteins
VP1-4, with many critical determinants for infection and immunity inherent in molecular constituents of the VP1 protein (Belsham, 1993). Seven distinct serotypes of FMDV, with indistinguishable clinical effects have been defined and namely types O, A, C, SAT 1, SAT 2, SAT 3 and Asia 1. The recovery from infection or protective vaccination with one serotype will not protect against subsequent infection with other serotypes, also within the same there is serotype a wide range of strains may occur. (Kitching et al., 1989 and Kitching, 1998). In Egypt, FMD has been recorded since 1950. Serotypes A and SAT-2 caused many outbreaks in 1953, 1958 and 1960 (Zahran, 1961), from then FMDV serotype 
"O" was the most prevalent in setting the disease among cattle and buffaloes, the routine prophylactic vaccination has been conducted with a locally produced serotype "O" vaccine (Moussa et al.,1979) . FMDV serotype A was the main cause of the disease outbreak in 2006 (Abdel-Rahman et al., 2006). In May 2006, bivalent inactivated FMD vaccine was locally produced and it contained both $\mathrm{O} 1$ and $\mathrm{A}$ local isolates and used for routine vaccination (Knowles et al., 2007). During 2012, there has been dramatic upsurge in FMD outbreaks, by a new virus strain known as SAT-2, so a trivalent vaccine containing $\mathrm{O}, \mathrm{A}$ and SAT2 local isolates was produced (FAO 2012, Shawky et al., 2013 , Laila et al., 2014 and Nader et al., 2014 ).The present study was carried out to detect FMDV antigen in lesions of clinical infected cattle and buffaloes in different localities (Menofia, Gharbia, Kalyuobia, Giza, Sharquia governorates), and identification of the isolated FMDV using serotyping antigen detection ELISA kit (IZSLER ELISA Kit) in order to identify the different factors influencing the prevalence of FMDV in this localities.

\section{MATERIAL AND METHODS}

\subsection{Sampling}

Thirty six clinical lesion samples (20 cows and 16 buffaloes) were collected from different localities (Menofia, Gharbia, Kalyoubia, ElreefELoropy (Giza) and Sharquia governorates) during the period from May 2014 to July 2015, the case history included (age, sex, species of animal, state of vaccination, season of sampling and type of the used vaccine). Tongue epithelium samples were collected from clinically infected animals for laboratory diagnosis and examined by 6 plates ELISA typing (IZSLER Kits). Samples were collected 72 hours after appearance of clinical signs; also udder and nasal lesion were collected from two infected animals. The samples were placed in a transport medium and stored at $-70^{\circ} \mathrm{C}$ till used for isolation and identification of virus by using FMD antigen serotyping ELISA.

\subsection{FMD antigen typing detection ELISA Kits}

The Kits were produced at IZSLER Biotech laboratory, pirbright institute, (UK).

\subsection{Preparation of tissue samples:}

One gram from the tissue was grinded using sterile sand with Veronal buffer in a sterile mortar, then use cooling centrifuged at 3000 rpm for 10 minutes. The supernatant was collected and filtered through Millipore filter $(0.22 \mu)$ and storage in small vials and kept at $-70^{\circ} \mathrm{C}$ until used.

\subsection{The procedure:}

It was carried outaccording to IZSLER Biotech Lab.

\section{RESULTS}

Our results in table (1) clarifying that in Gharbia governorate during 2014 the most prevalent serotype was (O) and in Kalyoubia governorate during 2015 serotype $(\mathrm{O})$ is the highest prevalence strain. In Menofia governorate during 2015, both serotypes $(\mathrm{O})$ and (SAT-2) appeared in the collected samples but serotype $(\mathrm{O})$ occur with higher prevalence than serotype (SAT2), also in the collected samples from Giza governorate, both (O) and (SAT-2) serotypes appeared, but (SAT-2) serotypes is the highest prevalence. In Sharquia governorate samples both serotypes (A) and (O) were isolated, but serotype $(\mathrm{O})$ is the highest prevalence rate. Our indicated that FMDV was detected in both vaccinated and un-vaccinated animals, but at higher prevalence in vaccinated animals $(36.1 \%)$. The obtained results showed that post vaccination infection in case of Triaphthovac vaccine (MEVAC) was (19.4\%), Polyvalent oil adjuvant vaccine "Abbassia" was (13.9\%) and Aftovaxpur vaccine (MERIAL) was (2.8\%) so Aftovaxpur becomes the best type of 
vaccine for using in the vaccination process. Higher prevalence rate of FMDV was detected during winter than summer by $(55.6 \%)$ and $(11.1 \%)$ respectively. The results in table (2) indicated that FMDV was detected in cattle samples more than buffaloes samples by (50\%) and (19.4) respectively. The results clarified that $1-2$ years old age is the most susceptible to FMDV than 4-5 months and 3-5 years old by $(52.8 \%), \quad(8.3 \%)$ and $(5.6 \%)$ respectively. The obtained results showed that higher prevalence was detected in lesion samples collected from females than males by $(36.1 \%)$ and $(30.6 \%)$ respectively. From table (3) indicated that during the period of our experiment FMDV serotype (A) occur with high frequency followed by serotype (SAT-2), the lowest frequency was of serotype (A) by $(62.5 \%),(33.3 \%)$ and $(4.2 \%)$ respectively.

Table (1) Effect of (locality, vaccination state, type of used vaccine and season) on prevalence of FMDV in clinically infected animals.

\begin{tabular}{|c|c|c|c|c|c|c|c|c|}
\hline \multirow[t]{2}{*}{ Factor } & \multicolumn{2}{|c|}{$\begin{array}{l}\text { Examined } \\
\text { samples }\end{array}$} & \multicolumn{3}{|c|}{$\begin{array}{c}\text { Number of +ve samples } \\
\text { serotype }\end{array}$} & \multirow[t]{2}{*}{$\%$} & \multicolumn{2}{|c|}{-ve samples } \\
\hline & No. & $\%$ & A & $\mathrm{O}$ & SAT-2 & & No. & $\%$ \\
\hline 1. Locality : & 36 & - & & & & & & \\
\hline Gharbia & 3 & 8.3 & - & 1 & - & 2.7 & 2 & 5.5 \\
\hline Kalyuobia & 4 & 11.1 & - & 2 & - & 5.5 & 2 & 5.5 \\
\hline Menofia & 9 & 25 & - & 5 & 2 & 19.4 & 2 & 5.5 \\
\hline Giza & 16 & 44.4 & - & 5 & 6 & 30.6 & 5 & 13.9 \\
\hline Sharquia & 4 & 11.1 & 1 & 2 & - & 11.1 & 1 & 2.7 \\
\hline \multicolumn{9}{|l|}{ 2. Vaccination state } \\
\hline Vaccinated & 22 & 61.1 & & 13 & & 36.1 & 9 & 25 \\
\hline Unvaccinated & 14 & 38.9 & & 11 & & 30.6 & 3 & 8.3 \\
\hline \multicolumn{9}{|l|}{ 3. Type of used vaccine } \\
\hline Triaphthovac "MEVAC" & 16 & 44.4 & & 7 & & 19.4 & 9 & 25 \\
\hline Polyvalent oil adjuvant "Abbassia" & 5 & 13.9 & & 5 & & 13.9 & - & - \\
\hline Aftovaxpure "MERIAL" & 1 & 2.8 & & 1 & & 2.8 & - & - \\
\hline \multicolumn{9}{|l|}{ 4. Season: } \\
\hline Winter & 28 & 77.8 & & 20 & & 55.6 & 8 & 22.2 \\
\hline Summer & 8 & 22.2 & & 4 & & 11.1 & 4 & 11.1 \\
\hline
\end{tabular}

Table (2) Effect of (species, age and sex) on prevalence of FMDV in clinically infected animals.

\begin{tabular}{|c|c|c|c|c|c|c|}
\hline \multirow{2}{*}{ Factor } & \multicolumn{2}{|c|}{ Examined samples } & \multicolumn{2}{|c|}{ Positive samples } & \multicolumn{2}{|c|}{ Negative samples } \\
\hline & No. & $\%$ & No. & $\%$ & No. & $\%$ \\
\hline 1. Species: & 36 & & & & & \\
\hline i. Buffaloes & 16 & 44.4 & 7 & 19.4 & 9 & 25 \\
\hline ii. Cattle & 20 & 55.6 & 18 & 50 & 2 & 5.6 \\
\hline \multicolumn{7}{|l|}{ 2. Age: } \\
\hline i. $4-5$ months & 5 & 13.9 & 3 & 8.3 & 2 & 5.6 \\
\hline ii. 1-2 years & 25 & 69.4 & 19 & 52.8 & 6 & 16.7 \\
\hline iii. 3-5 years & 6 & 16.7 & 2 & 5.6 & 4 & 11.1 \\
\hline \multicolumn{7}{|l|}{ 3. Sex: } \\
\hline i. Male & 16 & 44.4 & 11 & 30.6 & 4 & 11.1 \\
\hline ii. Female & 20 & 55.6 & 13 & 36.1 & 7 & 19.4 \\
\hline
\end{tabular}


Table (3) Frequency of different serotypes of FMDV

\begin{tabular}{lccc}
\hline $\begin{array}{l}\text { No. of total positive } \\
\text { samples }\end{array}$ & $\begin{array}{c}\text { No. of total positive of } \\
\text { A serotype }\end{array}$ & $\begin{array}{c}\text { No. of total positive O } \\
\text { serotype }\end{array}$ & $\begin{array}{c}\text { No. of total positive } \\
\text { SAT-2 serotype }\end{array}$ \\
\hline Gharbia governorate & Negative & One & Negative \\
Kalyoubia governorate & Negative & Two & Negative \\
Menofia governorate & Negative & Five & Two \\
Giza governorate & Negative & Five & Six \\
Sharquia governorate & One & Two & Negative \\
Total & 1 & 15 & 8 \\
Total positive (24) & $4.2 \%$ & $62.5 \%$ & $33.3 \%$ \\
\hline
\end{tabular}

\section{DISCUSSION}

Foot and mouth disease is the most contagious disease of mammals and has a great potential for causing severe economic loss in susceptible cloven hoofed animals. Our results agreed with Saber et al., (1997) who isolated FMDV serotype (O) from different outbreaks at Sharqia, Suez and Agga locality during 1972, 1987 and 1993 respectively. More over El- Bagoury et al., (2011) who concluded that FMDV serotype "O1" and A/EGY/2006 still existing and circulating at Menofia, Kalyuobia, Benisuef and Sharquia governorates. The phylogenic study showed that two FMDV serotypes isolated from governorates under study are highly related to the traditional isolated before in Egypt. Also Ahmed et al., (2012) and Valdazo et al., (2012) mentioned that during 2012; sever FMD outbreaks due to introduction of SAT-2 serotype for the first time in Egypt, initial cases were recognized at Upper Egypt including Sohage, Qena and Aswan governorates, more over further outbreaks of the disease were also suspected in Delta governorates. General organization for veterinary service (2014) found that serotype A was the most predominant serotype all over Egypt in 2013; Serotypes $\mathrm{A}$ and $\mathrm{O}$ were detected in all regions except in Western only serotype A. Both serotypes $\mathrm{A}$ and $\mathrm{O}$ are detected in Behera, Menofia, PortSaid, Dumyat and Kafr El sheikh, Serotype (O) was only represented in Giza and Sohag. Serotype SAT-2 was the most predominant in all regions January- March 2014 followed by serotype (O). Serotype
(O) was more concentrated in Delta while SAT2 was more detected in eastern, middle and south regions. Menofia was the only governorate which recorded the three serotypes (A, O, SAT2). Also Neeta et al., (2011), El-Sayed et al., (2012) and FAO (2012) mentioned that identification of isolated FMDV from collected samples of naturally infected calves by Indirect Sandwich ELISA revealed that 5 out of 20 infected calves were typed as FMDV serotype A while 15 isolates were typed serotype $\mathrm{O}$. These results were confirmed using PCR using the universal primer. Shawky et al., (2013) concluded from the results that serotype SAT-2 FMD virus is introduced to Egypt through live animal's importation, and the sever clinical signs occurred among cattle and buffaloes indicated that this virus does not circulate in Egypt before. OIE annual report (2006) and Nick et al., (2007) whose said that 15 outbreaks were reported in Egypt in January 2006 at Alexandria, Behera, cairo, Dakahlia, Dumyat, Fayoum, Ismalia and Menofia. By April 2006, 34 outbreaks of disease have been reported that affected $>7500$ animals and involved an additional governorate Kalyuobia. Abdel-Hamed et al., (2014) and Nader et al., (2014). Whose said that FMD SAT- 2 outbreaks were reported in shaquia (2012) and Laila et al., (2014) was recorded SAT-2 in Alexandria 2012, While there is no outbreaks reported in Gharbia and Kafr El Sheikh provinces. FMDV was detected in cattle samples more than buffaloes samples as the immunity of buffaloes is more than 
that of cattle and its susceptibility to disease is may be lower than cattle, this results is agreed with Ahmed et al., (2012) and Valdazo et al., (2012) which reported that the clinical picture of FMD in affected animals was characterized by severe clinical signs in cattle, buffalos, small ruminants, and in particular in very young animals. This results are agreed with Alexandrove et al., (2013) who reported that both mouth and foot lesions can occur in water buffalo, but the clinical signs are reported to be milder than in cattle, and lesions may heal more rapidly, as its resistance is higher than that of cattle. The result revealed that Aftovaxpur becomes the best type of vaccine for using in the vaccination process as it is hexavalent vaccine, its composition has new symbol code is (3039) which cover different subtypes of $(\mathrm{O})$ serotype which doesn't present in penta valent vaccine $+\mathrm{O}$ Manisa+ A Iran 05+ A Saudi 95 + Asia 1 + SAT-2, and made from double inactivated (BEI) antigen. $\mathrm{Al}(\mathrm{OH}) 3$ and purified saponin as adjuvants. Our results also agreed with Solyom and Gzelleng (1977) who recorded that the immunogenicity of FMD vaccines can be considerably increased by the use of proper adjuvant, in FMD vaccines. FMDV mostly occur during winter as the virus is sensitive to high temperature, the result agreed with Tomasula et al., (2007) who reported that at high temperature, there might be destruction of virus receptors, which ultimately declined its infectivity.

Our results concluded that the FMDV with its three serotypes (O, A and SAT-2) appeared in different localities under our study (Gharbia, Sharquia, Menofia, Kalyoubia and Giza), but the most predominant serotype was serotype (O). There are many factors which affecting the prevalence of FMDV as age, sex, species of animal, state of vaccination, season of sampling and type of the used vaccine. We recommended using of Aftovaxpure (MERIAL) vaccine as it gave the lowest post vaccination infection. The results clarified that 3-5 years old age is least susceptibility to infection as may be attributed to that they have complete mature immune system and have previous exposure to FMD infection or vaccination.

Finally, we concluded that, several precautions should be taken to prevent introduction of FMD into our country\& importation of live ruminants 8should be from free FMD countries.

\section{REFERENCES}

Abdel-Hamed, M.Y., Abou-Zeid, A.A., Eisa, I.M.; Hiam, M. Fakhry and Wafaa, M.I. El-Nashawy 2014: Application of recent methods for diagnosis of foot and mouth disease in cattle and buffaloes Zag. Vet. J. (ISSN. 1110-1458) 42 (2): 81-90.

Abdel-Rahman, A.O., Farag, M.A., Samira El-Kilany, Eman, M.A., Manal Abo El- Yazed and Zeidan, S. 2006: Isolation and identification of FMDV during an outbreak of 2006 in Egypt. Kafr El- Sheikh Vet. Med. J., 4(1):451-464.

Ahmed, H.A., Salem, S.A., Habashi A.R., Arafa, A.A. , Aggour, M.G. , Salem, G.H. ,Gaber, A .S .; Selem, O.,Abdelkader S. H.; Knowles, N. J.; Madi, M., Valdazo-Gonzalez, B., Wadsworth, J.,Hutchings, G.H., Mioulet, V., Hammond, J. M. and King, D. P. 2012: Emergence of foot and mouth disease virus SAT2 in Egypt during 2012 .Transbound. Emerg. Dis. Dec, 59 (6):476-81. doi $: 10.1111 /$ tbed .12015 .

Alexandrov, T., Stefanov, D., Kamenov, P., Miteva, A., Khomenko, S., Sumption, K., Meyer Gerbaulet, H., and Depner K. 2013: Surveillance of foot and mouth disease (FMD) in susceptible wildlife and domestic ungulates in southeast of Bulgaria following a FMD case in wild boar. Vet Microbiol. 2; 166(12):84-90.

Belsham, G.J. 1993: Distinctive features of foot-and mouth disease virus, a member of the picornavirus family; 
aspects of virus protein synthesis, protein processing and structure. Progress in Biophysics andMolecular Biology, 60: 241-260.

Coetzer, J.A.W.,Thomsen, G. R.,Tustin, R.C. and Kriek, N.P.J. 1994: Footand-mouth disease. In Infectious Diseases of Livestock with Special Reference to Southern Africa, J.A.W., Coetzer, G.R., Thomsen, R.C., Tustin and N.P.J., Kriek (Eds) Oxford University Press, Cape Town, 825852.

El-Bagoury, G.F., ElSayed, W.M., ElNahas, E.M., El-Habbaa, A.S. and Azab, A.H. 2011: Sequence analysis of vp1 gene foot and mouth disease virus serotype $\mathrm{A}$ and $\mathrm{O}$ isolates from different governorates in Egypt. Benha Vet. Med. J. Special Issue (i): 122-128.

El-Sayed, E., Mossad, W., Ali, S.M., Shawky, M. 2012: Studies on the duration of immunity induced in cattle after natural FMD infection and post vaccination with bivalent oil vaccine, Vet World, 5(10): 603-608.

FAO, 2012: FMD caused by serotype SAT2 in Egypt and Libya. A Regional concern for animal health in North Africa and the Middle East., Viol.25.FAO/OIE Global Conference on FMD Control in Bangkok which was held from 27-29 June 2012).

General Organization for Veterinary Services, Ministry of Agriculture and Lacrimation 2014.

Saber, El-Kilany, S., Abd El-Bary, Fawazy and Abdas 1997: The antigenic variation of FMDV of the last three isolates in Egypt. Vet. Med. J. Giza, 45(2): 175-186.

Shawky, M., Abd El-Aty, M., Hiam, M. Fakry, Hind, M. Daoud, Ehab ElSayed, I., WaelMossad, G., Sonia, A. Rizk, Abu-Elnaga, H., Mohamed, A.A., Abd El-kreem, A. and Farouk, E.M. Veterinary Serum and Vaccine Research Institute, Abbasia, Cairo, 2013: Isolation and Molecular
Characterization of Foot and Mouth Disease SAT2 Virus during Outbreak 2012 in Egypt. P.O. Box:131- Fax: (202) 234283210

Solyom, F. and Czellenz, M. 1977: Studies on correct quantitative relation of antigen components in mono, and trivalent FMD vaccine preparations. Int. Sym. on FMD, Lyon Develop. Biol. Stand., 35: 289-294.

Tomasula P.M., MF Kozempel, R.P. Konstance, D. Gregg, S. Boettcher, B. Baxt and L.L. Rodriguez, 2007: Thermal inactivation of foot and mouth disease virus in milk using high-temperature, short-time pasteurization. J Dairy Sci, 90: 32023211.

Kitching, R.P., Knowles, N.J., Samuel, A.R. and Donaldson, A.I.1989: Development of foot-and mouth disease virus strain characterization a review. Tropical Animal Health and Production, 21: 153-166.

Kitching, R.P. 1998: A recent history of foot-and mouth disease. Journal of Comparative Pathology, 118: 89-108.

Knowles, N.J., Wadsworth, J., Reid, S.M., Swabey, K.G., El-Kholy, A.A. ElRahman, A.A., Soliman, H.M., Ebert, K., Ferris, N.P., Hutchings, G.H., Statham, R.J., King, D.P. and Paton, D. 2007: Foot and mouth disease virus serotype A in Egypt. Emerg. Infect. Dis., 13 (10):1593-1596.

Laila, I., EL-Shehawy, Hany, I. AbuElnaga, Sonia, A. Rizk, Ahmed, S. Abd El-Kreem, Mohamed A.A. and Hossam, G. Fawzy 2014: Molecular Differentiation and Phylogenetic analysis of the Egyptian foot-andmouth disease virus SAT2 . Arch Virol 2014 Volume 159.Number 3 March 2014: 437-443.

Moussa, A.A.M., Daoud, A., Hussein, K., Fahmy, F., El-Kilany, S. and ElShehawy, L. 1979: Prevalence of FMD in Egypt. Presented and accepted for publication at the 14th Arab Vet. Cong., 14: 39-50. 
Nader, M. Sobhy, Sunil, K. Mor, Mohammed, E.M. Mohammed, Iman, M. Bastawecy, Hiam, M. Fakhry, Christiana, R.B., Youssef, and Sagar, M. Goyal 2014: Phylogenetic analysis of Egyptian foot and mouth disease virus endemic strains. Journal of American Science 2014, 10(9) 133138

Neeta Longjam, Deb, R, Sarmah, A.K., Tayo, T., Awachat, V.B. and Saxena, V.K. 2011: A Brief Review on Diagnosis of Foot-and-Mouth Disease of Livestock: Conventional to Molecular Tools. Veterinary Medicine International Volume 2011, Article ID 905768, 17 pages, doi:10.4061/2011/905768.
Nick, J.K., Alaa, A.E., Hatem, M.S., Nigel, P.F., Geoffrey, H.H. and Parker, D. P. 2007: Foot and mouth disease virus A in Egypt. Emerging Infectious disease .13: 1593-1596.

OIE annual status, 2006: Disease information 16 February 2006, Information Dept.@OIE.Int,19.

Valdazo-Gonzalez, B., Knowles, N.J., Hammond, J. and King, D.P. 2012: Genome sequences of SAT-2 foot and mouth disease viruses from Egypt and Palestinian Autonomous Territories (Gaza strip). J. Virol. 86: 8901-8902.

Zahran, G.E.D. 1961: FMD in southern region of U.A.R. Bull. Off. Int. Epiz., 390393. 